\title{
Emesto Wauthion
}

\section{Crítica a la postmodernidad y al neoliberalismo. Una aproximación al pensamiento de Franz J. Hinkelammert}

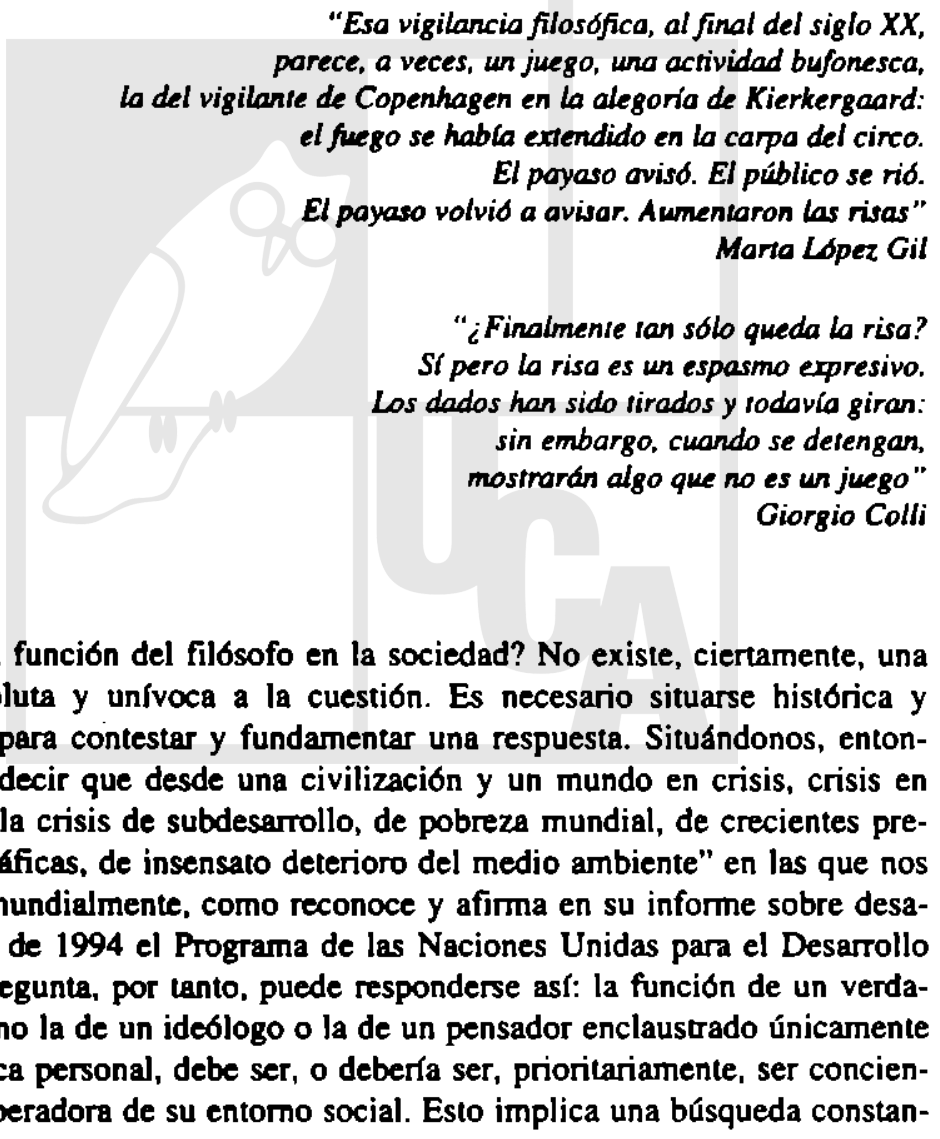

¿Cuál es la función del filossofo en la sociedad? No existe, ciertamente, una respuesta absoluta y unfvoca a la cuestión. Es necesario situarse histórica y culturalmente para contestar y fundamentar una respuesta. Situándonos, entonces, podemos decir que desde una civilización y un mundo en crisis, crisis en plural, como "la crisis de subdesarrollo, de pobreza mundial, de crecientes presiones demográficas, de insensato deterioro del medio ambiente" en las que nos encontramos mundialmente, como reconoce y afirma en su informe sobre desarollo humano de 1994 el Programa de las Naciones Unidas para el Desarrollo (PNUD), la pregunta, por tanto, puede responderse asi: la función de un verdadero filossofo, no la de un idélogo o la de un pensador enclaustrado únicamente en su metaffsica personal, debe ser, o deberia ser, prioritariamente, ser conciencia crítica y liberadora de su entomo social. Esto implica una búsqueda constan- 
te de la verdad en la realidad en general, pero, sobre todo, en la realidad poif́tica. ¿Por qué? Porque lo político, como decía el fillósofo salvadoreño Ignacio Ellacurfa, si bien no es lo más importante, ś́ es lo más determinante en toda realidad histórica y cultural, ya que es en las decisiones y opciones políticas donde se juega el presente y futuro de loda comunidad humana.

Degraciadamente, los análisis y críticas del filosofo, por muy certeros y próximos a la realidad que sean, a lo largo de la historia siempre han sido mal recibidos por los detentores del poder, particularmente en los paises sometidos a dictaduras y sistemas autoritarios. Pues toda reflexión crítica sobre la realidad social en que se vive ha sido considerada, en las sociedades donde se ha reprimido la libertad de pensamiento y acción, como "subversiva". Y, desgraciadamente, ésta fue la regla en muchas naciones latinoamericanas, hasta que a finales de los ochenta, la democracia comenzo a despertar y ejercerse paulatinamente en nuestra América. Pero antes y durante la década de los ochenta, el filósofo o el pensador crítico sufrió, en nuestros pueblos, la persecusión, el destierro o su acallamiento tolal por medio de una muerte premeditada y violenta. Un ejemplo pat́tico, que se puede perdonar pero nunca olvidar, se vivió en nuestro país con Ignacio Ellacurfa, Ignacio Martín-Baró y Segundo Montes, quienes, junto a otros tres hermanos jesuitas y dos humildes mujeres de la Universidad Centroamericana "José Simeón Cañas" (UCA), fueron bárbaramente masacrados el 16 de noviembre de 1989. Sl, acusados de "subvertir" el orden público con sus acciones y pensamientos críticos, estos intelectuales fueron brutal y cobardemente asesinados por un escuadrón militar que, lejos de actuar solo, más bien ejecutaba órdenes superiores: las del alto mando del ejército salvadoreño, cuyos jefes militares eran respaldados y obligados a su vez, por el poder económico y politico más retrógrado e intolerante de ese entonces en El Salvador...

Pero, hoy en día, a finales de los noventa, década en que una vida calificada de postmodema parece permear todas las culturas del planeta, y en mundo en el que casi todos los gobiernos, sectores, partidos y dirigentes polf́ticos de distintas tendencias pregonan y legitiman la "democracia" como única salida a la vida política moderna, aunque no exista unanimidad en cuanto a lo que se entiende por "democracia", si bien el filosofo, o el pensador crítico, sigue siendo una molestia, al menos se le permite hablar, pues, ya no parecen haber mordazas, aparentemente, en nuestros países latinoamericanos, y tampoco en muchos otros del planeta... Mas, por supuesto, no se toma en serio su filosofar; aunque con éste demuestre y advierta que, de seguir con el estilo de vida mercadocentrista que llevamos, en el que predomina una racionalidad puramente economicista y que es la raíz de las crisis que aquejan a la humanidad, nos conduzcamos, como humanidad, a una autodestrucción total. No obstante, a pesar del cinismo y el desprecio con que hoy lo tratan los dueños del poder económico y político, tanto nacional como internacionalmente, el filosofo no puede guardar para sí la verdad: la hace pública. Lanza repetidos gritos vitales de alerta por detener el juego 
mortal en que el mundo ha caldo, y trata, a su vez, de orientar a los hombres hacia la búsqueda de otra altemativa de vida y sociedad planetaria.. Pero los que tienen el poder para decidir y optar por un cambio de esta naturaleza en el mundo no quieren escuchar, y la humanidad entera, a su vez, parece que está demasiado entretenida entre una producción y un consumo que cree infinitos para desear cambiar también y dejar de jugar con su vida misma y con la del resto de seres vivientes sobre la Tierra. Quizá, entonces, la mejor descripción de la función crf́tica o vigilante del filósofo en la postmodernidad sea tsta que nos ofrece la filosofa argentina Marta López Gil: "Esa vigilancia filosofica, al final del siglo XX, parece, a veces, un juego, una actividad bufonesca, la del vigilante de Copenhagen en la alegorla de Kierkergaard: el fuego se habla extendido en la carpa del circo. El payaso aviso. El público se rió. El payaso volvió a avisar. Aumentaron las risas"!.

Franz J. Hinkelammert es uno de esos filosofos vigilantes de nuestro tiempo. Es un gran critico de esta época de crisis, que está en boga llamar "postmodernidad". Presentar y tratar de no interpretar y juzgar en lo posible su pensamiento es nuestro propósito. Pues nos mueven fines meramente didácticos en el campo de la antropolog/a filosofica y de la filosofla política, con la esperanza de interesar y motivar a los estudiantes, tras la lectura de este artículo, a leer y conocer directamente los escritos de este gran intelectual. Pero, para hacer más comprensible el contexto histórico y cultural que analiza críticamente Hinkelammert, y que desde las materias mencionadas interesa estudiar, hemos creldo necesario dar una breve explicación, antes de presentar una idea aproximada o esbozada de nuestro autor y su obra, sobre los conceptos "modernidad" y "postmodemidad".

\section{La idea de postmodernidad}

Postmodernidad se opone a modernidad. Es la superación, se supone, de la etapa histórica moderna. Postmodernidad es el nombre de moda con el que intelectuales de distintos ámbitos califican la nueva era que, afirman sus defensores, estamos viviendo mundialmente, por lo menos, dicen, desde finales de los años setenta. Pero, ¿por qué ya no estamos en la modernidad sino en un nuevo liempo denominado postmodemidad? ¿Cómo llegamos a la postmodernidad y qué distingue esla aparente nueva época de la inmediata anterior?

La historia occidental suele dividirse en tres grandes periodos: la antigüedad, el medioevo y la modernidad. La antigüedad se remonta hasta la aparición de la escritura, es decir, hace unos 3000 años a. de C., pero al hablar de antigüedad también nos referimos a un momento especlfico: la edad clásica del mundo griego y romano. Esta etapa se extiende desde el siglo VI a. de C. hasta el siglo V d. de C. Se trata de un período cosmocéntrico. Todo está en función del cosmos o naturaleza. En este contexto histórico, por tanto, primero está el cosmos, luego el Hombre y por último la divinidad en su orden de importancia e 
interts para el filosofar. Pero al acabar el mundo antiguo, con la carda del Imperio Romano de Occidente, en el aflo 476 de nuestra era, sigue un nuevo tiempo: el medioevo, un período también diflcil de delimitar. No obstante, por lo general puede decirse que la época medieval cubre desde el siglo $\mathrm{V} \mathrm{d}$. de $\mathrm{C}$. hasta el siglo XIV. Esta es una etapa teocéntrica. Todo gira en tomo a Dios. Dios es lo principa, después el cosmos o mundo y, en último término, el Hombre. Al entrar en crisis el universo cristiano-medieval, durante el siglo XTV, se inagura otra tpoca: la modemidad, cuyo centro de interés, aparente, es el ser humano. En principio, lo fundamental es el Hombre, le sigue el cosmos y al final está Dios. Nace asl, con la modemidad, una época que se dice antropocéntrica.

La modernidad se gesta durante los siglos XV y XVI, es decir, durante el Renacimiento. Pero su natalicio se da, propiamente, en el siglo XVП, con la filosofla de Descartes (1596-1650) y la nueva ciencia de Galileo (1564-1642), Kepler (1571-1630) y Newton (1642-1727). Su edad adulta la alcanza en el siglo XVIII, o sea, con la Ilustración o Siglo de las Luces. Entre algunas de las caracteristicas de la sociedad y el pensamiento ilustrados podemos mencionar: (1) un mundo más laico y profano; (2) confianza en la razón y las ciencias, y en la capacidad de éstas para organizar la sociedad y transformar la naturaleza racionalmente; (3) fe en que la realidad natural y cultural es verdaderamente racional, es decir, que el mundo es lógico y racional; (4) creencia en la idea de progreso, en tanto que cada generación humana superara y será mejor que la inmediata anterior; (5) universalización de la cultura occidental, o sea, se cae en un etnocentrismo, y Occidente es visto como la civilización por excelencia que debe ser seguida e imitada por los demás pueblos.

El filosofo ilustrado Inmanuel Kant (1724-1804), al plantearse la pregunta qué es la Ilustración, responde: "La Ilustración es la salida del hombre de su autoculpable minorla de edad. La minorfa de edad significa la incapacidad de servirse de su propio entendimiento sin la ayuda de otro. Uno mismo es el culpable de esta minorfa de edad cuando la causa de ella no reside en la carencia de entendimiento, sino en la falta de decisión y valor para servirse por sf mismo de él sin la guía de otro. Sapere aude! ¡Ten valor de servirte de tu propio entendimiento!, he aqu( el lema de la Mustración'"2. El lema es, pues, ¡Atrévete a pensar!, iatrévete a usar la razón!

Pero además de esta fe en la razón, otra idea fundamental de la época fue la idea de progreso. En un texto de un tal Abbe Morellet, encontramos el sueño de un progreso de racionalización sin límites: "Confiemos en la mejora del destino humano como consecuencia del progreso de la Ilusuración y del esfuerzo de los instruidos; confiemos en que los errores, $e$ incluso las injusticias de nuestra época, no nos aparten de esta consoladora esperanza. La historia de la sociedad presenta una alternativa continua de luz y tinieblas, razón y absurdo, humanidad y barbarie; pero, a lo largo de los tiempos, podemos ver que el bien aumenta 
gradualmente en proporción siempre creciente... Concedamos que el hombre avanza, aunque lentamente, hacia la luz y la felicidad"'s.

Otros que creyeron en una historia progresiva y soñaron con un futuro siempre de felicidad y luz, fueron los pensadores franceses Turgot, quien escribió el Discurso sobre los progresos sucesivos del espiritu humano, en 1750, y Condorcet. autor de la obra Esbozo de un cuadro histórico de los progresos del espíritu humano, de 1794. En ella, Condorcet afirma: "Llegara el momento en que el Sol no alumbre sobre las tierras más que a hombres libres, los cuales no conocerán más señora y maestra que la Razón, y en el que los tiranos y esclavos no existirán más que en la historia y en los teatros"'.

No obstante, el optimismo de la modernidad no durará por mucho tiempo y sus promesas e ideales comenzarán a ser criticados seriamente desde mediados del siglo XIX. Las primeras críticas a la llustración, o a lo que se puede denominar una razón ilustrada, son hechas por filósofos herederos de la misma llustración. Al idealismo de la razón ilustrada se opone una razón critica con filosofos materialistas y vitalistas como Karl Marx (1818-1883) y Friedrich Nietzsche (1844-1900), y más tarde, ya entrado el siglo XX, con el psicoanalista Sigmund Freud (1856-1939) y freudomarxistas como Max Horkheirmer (1895-1973), Theodor Adorno (1903-1969), Herbert Marcuse (1898-1979), Eric Fromm (19001980 ) y otros. Y es en el contexto de una segunda crítica a los principios y valores de la Ilustración que va a ir surgiendo la idea de una "postmodernidad".

Entre los primeros en utilizar el término postmodernidad están dos poetas y escritores franceses: Charles Baudelaire (1821-1867) y Theophile Gautier (18111872). Ambos autores pertenecen al romanticismo, un movimiento literario muy influyente en las sociedades occidentales de la primera mitad del siglo XIX, y que constituy6, en parte, una conriente reaccionaria a la vida moderna. Baudelaire, por ejemplo, empleó el término en 1864, y fue un gran crítico del utilitarismo, la mecanización y el llamado progreso de su época la modernidad: "La mecanización... nos americanizará. El progteso nos atrofiara"'s.

Sin embargo, la divulgación del conceplo postmodemidad, a nivel de debate interdisciplinario y que planteó la polémica modernidad-postmodernidad, se originó y desarrolló en Francia, a finales de los setenta, con los postesiructuralistas franceses. En efecto, en 1979 se publica la obra del filosofo Jean-Francois Lyotard, La condition postmoderne $e^{\phi}$. Dicha polémica pasó inmediatamente a Alemania y Estados Unidos, y luego al resto de las sociedades occidentales. Como filosofos postmodernos pueden considerarse, por ejemplo, los franceses Michele Foucault (1926-1984), Gilles Deleuze (1925-), Jean-Francois Lyotard (1924-), Gilles Lypovetsky, Jacques Derrida (1930-), Jean Baudrillard (1929-), los italianos Gianni Vaütimo (1936-), Umberto Eco (1932-), o el estadounidense Richard Rorty (1931-). Entre los que se oponen a éstos y sostienen que la modernidad es un proyecto inconcluso está, entre otros, el filosofo alemán Jürgen Habermas (1929)7. 
Hay quienes tienen como precursores de la llamada postmodemidad a los filosofos alemanes Friedrich Nietzsche (1844-1900) y Martin Heidegger (18891976). Se considera que ambos posibilitaron las bases del pensamiento postmodemo. Nietzsche con su critica radical a toda la cultura occidental y su anuncio de una época nihilista: "El nihilismo está a las puertas..."." Heidegger por sus reflexiones en torno a un mundo tecnocéntrico: "Por lodas partes quedamos sin libertad encadenados a la técnica, sea que apasionadamente la afirmemos o la neguemos..."'.

Según los analistas, algunos de los rasgos y lemas fundamentales de la postmodernidad son: (1) crítica a la modernidad y sus mitos, como el progreso, la razón ilustrada y sus pretensiones de objetividad, verdad y universalidad; (2) mística del ocaso; (3) imperialismo económico; (4) ya no hay futuro, todo es presente; (5) final del Estado de Bienestar; (6) cultura "light"; (7) neoliberalismo total; (8) ocaso del arte; (9) crepúsculo de las ideologías; (10) pérdida de todo referente real; (11) era del vacio; (12) muerte de Dios; (13) muerte del hombre; (14) muerte del simbolismo; (15) capitalismo sin alternativas; (16) fin del mito revolucionario; (17) fin de la historia; (18) cultura de la desesperanza; (19) imperio de lo efímero; (20) mundo sin utopías; etc. Todo esto y más es lo que se dice y afirma sobre lo que experimentamos y vivimos en el momento presente. $Y$ si las mencionadas caracteristicas dibujan un panorama pesimista y desolador, éste adquiere adernás un aire apocalfptico en cuanto que la postmodernidad coincide, paradójicamente, con el final de un siglo y el principio de un nuevo milenio.

No es nueștro propósito ahondar más en el asunto, y hacer un análisis detallado de la llamada postmodernidad, entrando en el debate modernidadpostmodernidad 10 . Con todo lo anterior sólo pretendemos situarnos epocalmente y fundamentar mejor nuestro tema, de la manera más didáctica posible, y así esperar una mayor comprensión del mismo por parte de nuestros lectores. El objetivo de este artículo es, más bien, analizar críticamente uno de los problemas capitales de nuestro momento, llámesele postmodemo o no, y es éste: el problema de un mundo sin más alternativa que el capitalismo neoliberal. Se trata del problema de la esperanza y la utopía en la sociedad actual. Responder de manera crítica a estos problemas, desde una aproximación a la filosofía y los análisis científico sociales de Franz J. Hinkelammert, es, por consiguiente, nuestra meta, ya que este autor ha trabajado, desde hace varios años, una conceptualización trascendental de lo utópico, es decir, ha venido haciendo una crítica a la razón ulópica misma con el fin de analizar los fundamentos del pensamiento social actual.

\section{Unos datos sobre Hinkelammert}

Realmente, Franz J. Hinkelammert es una persona que no necesita mucha presentación en el medio intelectual latinoamericano. Es un economista de for- 
mación, pero también un filósofo y teólogo por ejercicio y vocación ampliamente conocido en Centroamérica. Realiza una crítica radical, desde un pensamiento maxxiano critico y abierto, al capitalismo neoliberal y a la sociedad occidental en crisis. Dialoga y polemiza en sus obras con Marx, Nietzsche, Weber, Heidegger, Popper, Hayek, Apel, Lyolard y otros. Su origen es alemán, pero es considerado un verdadero latinoamericano de corazón y opción. Sus libros son profundos y serios, pero escritos con gran sensibilidad, detalle y humor desde la realidad histórica y cultural latinoamericana.

Para esta breve aproximación a su pensamiento nos hemos servido, especialmente, de nuestros apuntes de clase de los cursos impartidos por él en el Doctorado en Filosofía Iberoamericana, de la Universidad Centroamericana "José Simeón Cañas" (UCA), durante el segundo semestre de 1997. Y, asimismo, de sus dos últimos libros: Culsura de la esperanza y sociedad sin exclusión, escrito en 1995; y Determinismo, caos, sujeto. El mapa del emperador, del año 1996.

En lo posible, lejos de hacer una interpretación personal de la obra de Hinkelammert, buscamos presentar algunas ideas de su rico y profundo pensamiento, tomadas literalmente de sus textos arriba mencionados, para exponer con la mejor claridad y fidelidad que se pueda sus planteamientos filosóficos y cientifico-sociales.

\section{El eterno retorno de lo nuevo}

Al ocuparse de la postmodernidad, Hinkelammert no sigue una moda intelectual. Su intención filosófica es más bien responder a las pregunlas: ¿por qué cs necesario terminar con la modernidad? y, ¿por qué la posımodernidad es tan moderna? Es decir, le preocupa saber por qué la modernidad ha llegado a su fin y no puede sostenerse más. Asimismo, se pregunta: ¿por qué está tan de moda hablar de postmodernidad?, ¿qué es lo que ésta ofrece con toda su orquestación publicitaria? y, ¿qué es lo que se esconde realmente tras ella? Su respuesta no larda. A su juicio. puede ser cierto que hoy en día no estemos viviendo una época de cambios sino más bien un cambio de época, el cual es muy "moderno" calificarlo de "postmoderno". Sin embargo, llamar posmoderna a la nueva época, dice, no sorprende, puesto que no es más que una tautología, un nombrar los liempos con distinto término aunque las cosas continuen igual, pues, la época presente, la postmodernidad, es una continuación de la anterior, la modernidad; salvo por la velocidad con que los fenómenos suceden. Por ello sostiene que en los años noventa en que nos encontramos:

"La velocidad del tiempo es la velocidad de una bicicleta de gimnasia. Está puesta en el baño, uno va a velocidades altas, pero no se mueve. Se introducen los cambios, pero nada cambia, excepto la velocidad de algo que no se mueve. Sin embargo este movimiento nos agota a todos. Vivimos lo que Walter Benjamin llamaba el eterno retorno de lo nuevo"". 
Para nuestro filosofo, la postmodemidad no es más que un publicitario camuflaje de la eternización de una modernidad burguesa. Y, tras éste análisis, y con no menos humor y realismo, nos cuenta la siguiente anécdota para explicarnos mejor la realidad histórica y cultural de nuestra época:

"Un antiguo sabio, al maldecir a su enemigo, lo amenazo: Quiero que vivas en tiempos interesantes. Nosotros vivimos bajo está maldición. El tiempo es demasidado interesante, pero nuestro deber es asegurar a nuestros hijos para que vivan tiempos menos interesantes. La modernidad se, ha puesto demasiado interesante, y la postmodernidad quiere hacerlo más interesante todavía. El antiguo Egipto vive dos milenios, sin que pase gran cosa. Algo parecido ocurre con la historia de China, que pasa tres milenios, sin que haya cambios estrepitosos. ¿Cómo podemos lograr recuperar tiempos pareçidos? Doscientos cincuenta años de modernidad -0 , según se quiera, quiniéntoo- nos han llevado a temblar por el futuro de la próxima generación y de todo el planeta. Evidentemente, hace falta algo que sea diferente a esta modernidad, tan interesante y tan amenazante. Tenemos que salir de esta maldición por los tiempos interesantes"'?

Los sueños de la modernidad renacentista e ilustrada, como los de crear un mundo antropocéntrico, basado en la razón y en un progreso cientifico-lécnico cada vez mayor, han dejado de ser simples sueños en estas décadas de fin de siglo, y se han vuelto, desgraciadamente, verdaderas pesadilles. Es esceserio despertar; pero las pesadillas se han convertido en un entretenimiento demasiado interesante para abandonarlas. Hinkelammert sostiene que la modemided ha caido en un juego tecnocentrista y mercadocéntrico peligroso, en nombre de la competitividad y sus valores supremos: la eficiencia y la racionalided económica. Ha llegado a montar una especie de carrusel suicida. Está jugando con la vida de la humanidad y del planela entero al perseguir como fin último un crecimiento económico insaciable:

"La modernidad desemboca en un carrusel autodestructivo, La política neoliberal no hace otra cosa que impulsar la velocidad vertiginosa con la que el carrusel se mueve. Se trata de un carrusel de la muerte"13.

Son dos los motores, nos dice, que le imprimen velocidad a este carrusel de la muerte. El primero es el crecimiento económico que propicia la gran industria moderna del Primer Mundo, con su idea de un mercado total y global, aparentemente para beneficio de todos. Pero, en la cruda realidad de los hechos, sólo unos pocos gozan de este sisterna economicista y desarrollista que conduce a la exclusión de las grandes mayorías humanas del planeta, sumiendolas en una desesperación que si es realmente total al hacerlas sufrir hambre, miseria, frío, ignorancia, etc. Mas este sistema inhumano e injusto no sólo expulsa, excluye y destruye a grandes partes de la población humana, sino también la base que posibilita la vida misma: 
"La expulsión y consiguiente exclusión de la población lleva a una expulsión, exclusión y destrucción de la naturaleza"le.

El otro motor, por paradójico que parezca, proviene de los mismos excluidos y desesperados que produce el sistema capitalista, pues, estos humanos empobrecidos buscan sobrevivir por cualquier medio posible a su alcance:

"Dada su situación desesperada, y provocada por ella, desarrollan estrategias desesperadas de sobrevivencia en la misma dirección en que se conduce el crecimiento económico. Esta estrategia fragmentaria de sobrevivencia también amenaza a la naturaleza que, por otro lado, es destruida por las empresas en su afán de maximizar su crecimiento. El mismo crecimiento exagerado de la población mundial es hoy el resultado de estas estrategias desesperadas de sobrevivencia. Así, todo el conjunto social se subvierte y produce el presente estado de anomia generalizada. La droga y el crimen no son sino epifenómenos de este proceso de destrucción mutua. Por otra parte, las migraciones incontenibles desde el Tercer Mundo hacia el mundo desarrollado, promovidas por los excluidos de la tierra y que subvierten los sistemas sociales existentes allá, demuestran que cada vez más vivimos en un solo mundo cuya sobrevivencia es el problema de todos"'s.

Este es el terrible remolino de aguas negras en el que se ha convertido la modernidad, bajo el nombre de postmodemidad. Todo es arrastrado hacia su centro, y su centro es el mundo del mercado total, con su competitividad, eficiencia y racionalidad económica. La modernidad ha dejado de tener como centro de interés al Hombre. Ya no es un mundo antropocéntrico. Hoy es el mercado y la técnica lo principal; no el Hombre. Vivimos un mercadocentrismo, un capitalocentrismo que nos está arrastrando a todos a una vorágine mortal.

¿Hay todavfa esperanzas ante un mundo que tiene como mistica el suicidio? Esta es la pregunta capital del momento. Pero antes de responderla, siguiendo a nuestro autor, es importante analizar ciertos antecedentes a la situación presente, para comprender mejor por qué la sociedad actual, llarnada postmoderna, se presenta como un mundo sin más alternativa que la suya: el capitalismo neoliberal.

\section{1989: un referente histórico}

Tras el colapso del socialismo real, y la caída del muro de Berlín en 1989, se pone fin a la Guerra Fría y se entra en una nueva fase histórica mundial. Se deja el mundo bipolar del conflicto Este-Oeste, que dividía el planeta en dos bloques. A un lado estaba el de los palses capitalistas o Primer Mundo. Al otro el de las naciones socialistas o Segundo Mundo. Pero en medio de ambos, se encontraban, como campo de batalla, los países empobrecidos y al margen del poder económico, militar y tecnocienúfico mundial, es decir, el Tercer Mundo. Una vez desaparecida la Guerra Fría, se penetra, por tanto, en un mundo unipolar, en 
el cual, el sisterna capitalista se presenta como el vencedor y como el modelo de sociedad, desarrollo y vida que hay que seguir a nivel planetario. Se sale, pues, de una crisis pero para entrar inmediatamente a otra que quizá es peor.

Cierto, la humanidad ya no corre el riesgo de una guerra nuclear, como sucedfa con las enfrentadas superpotencias de entonces. Mas se pasa a otra crisis, no menos importante y peligrosa que la anterior: una crisis de civilización. El estilo de sociedad, desarrollo y vida de las naciones del Primer Mundo, hoy llamado Norte, que agrupa, más o menos, un 30 por ciento de la población mundial, no es universalizable a la humanidad. Es decir, ese modelo no puede universalizarse al Tercer Mundo, ahora conocido como Sur, y que alberga cerca del 70 por ciento o más de los seres humanos que pueblan el planeta ${ }^{16}$. Pues hacer extendible el modelo de sociedad, desarrollo y vida del "Norte de los pocos con mucho"' al "Sur de los muchos con poco"'t" no es posible ni deseable, ni social ni ecológicamente. Y si no es extendible a toda la humanidad es porque tal modelo, como dice el economista nicaragilense Xavié Gorostlaga, tiene "Ilmites ecológicos, poblacionales y por ser esiructuraimente contradictorio. Contradictorio entre los requerimientos de la acumulación progresiva que exige ese modelo, con la concentración creciente del capital, la tecnología y el poder en el Norte, y la exclusión de las mayorlas del Sur que exigen no sólo la sobrevivencia, sino la participación y un nivel de vida humana que permita la democracia y la paz"'t". Esto indica, por consiguiente, que hemes tentendo a una crisis de civilización: la crisis de la cultura occidental, con su moddo civiltzacional inhumano, injusto e insostenible. Por ello, asegura Hinkelamnert:

"Lo que enfrentamos no es sólo una crisis del capitalismo, sino una crisis del concepto fundante de la modernidad. Se trata del concepto de la armonia inerte entre el progreso técnico y el progreso de la humanidad, mediatizada por un marco institucional como el mercado o el plan cuntrit: La krisis del capitalismo se ha transformado en una crisis de la propia ctvilliencion occidental"20.

Sin embargo, occidente y su capitalismo neoliberal no parecen entrar en razón. Tras el fracaso del llamado socialismo real o histórico, la parranda en occidente no termina. Embriagados totalmente por el triupfo del capitalismo, el Primer Mundo no cree haber cerrado un capítulo de la histone, sino más bien haber llegado al final de la historia misma con el capitalismo neoliberal como modelo definitivo de sociedad, desamollo y vida para la humanided.

Para Hinkelammert, el año 1989 acaba con un proceso que se habra iniciado desde los años setenta, como estrategia para un desarrollo definitivo del sistema capitalista. Refiriéndose a tales años explica:

"Esta es la década de reestructuración del sistema capitalista mundial en la que se produce un corte entre el capitalismo de reformas anterior, $y$ un nuevo capitalismo extremo y desnudo que se implanta mundialmente en el curso 
del decenio de los ochenta en nombre de los <<ajustes estructurales〉> y de la globalización y homogeneización del mundo por vía de los mercados. Hoy es común referirse a ese capitalismo, sin mayor precisión, como neoliberalismo. Se trata de un capitalismo de tábula rasa que abandona toda perspectiva de evolución social en favor de su política <<de choque>>. Es un capitalismo que Milton Friedman, uno de los principales representantes de este nuevo capitalismo, llega a llamar <<capitalismo total〉>.

Con la caída del muro de Berlín en 1989, este capitalismo total ve llegado su uriunfo definitivo. Celebra el $<$ fin de la historia», más allá del cual la humanidad no puede aspirar a nada nuevo. Cree tener en su bolsillo todo un futuro humano por venir. Se establece un imperio para el que no existe ningún competidor, y que no deja por fuera nada en la tierra. Y donde podrran producirse grietas, el imperio se proclama el señor: The west against the rest (El oeste en contra del resto: Huntington)"21.

Ciertamente, el capitalismo neoliberal se impone como modelo universal de sociedad, desarrollo y vida en el mundo. El Departamento de Estado del gobierno de Estados Unidos no sólo lo celebra sino que elabora "toda una filosoffa" con la que quiere dejar demostrado que con el sistema capitalista neoliberal, la humanidad ha llegado al "fin de la historia". En efecto, es en agosto de 1989 que, uno de sus burócratas, el ideologo Francis Fukuyama, publica el articulo The End of History? ( ${ } E l$ fin de la historia?), en la revista The National Interes ${ }^{22}$. En este escrito, y luego en su libro de 1992. The end of history and last man (El lin de la historia y el último hombre), Fukuyama hace una interpretación, bastante caprichosa por cierto, de las tesis del filosofo alemán George Wilhelm Friedrich Hegel (1770-1831), y de ciertas ideas de Niezsche, para clausurar la historia humana y negar asi cualquier otra alternativa futura de sociedad que no sea la "democracia neoliberal".

Para dar una breve idea, hay que decir que el sistema hegeliano es una ciencia de lo Absoluto, es decir, de la Razón o Idea, y una filosoffa de la historia universal. La Razón o Espíritu Absoluto se autorrealiza en los hechos concretos y finitos de la historia humana. Todo lo que acontece en la historia es racional y está debidamente orientado por el Espíritu Absoluto. Se trata de una visión teleológica o finalista de la historia. Y el fin al que se dirige la historia, para la realización misma del Espíritu Absoluto, es el Estado, porque con esta institución los hombres se realizan tomando conciencia de su libertad. Para Hegel, la historia es un sistema en progreso que avanza hacia la conciencia de la libertad. Hay tres perfodos en este proceso. El primero lo constituye la historia de Oriente (China, India, Egipto, Asia Menor, etc...), que se caracteriza por una falta de libertad, por lo que constituye la infancia de la historia. El segundo es la historia de Grecia y Roma, donde nace la idea de libertad, pero sólo para unos hombres, los ciudadanos, por lo que tal etapa representa la adolescencia de la historia. La 
tercera es la de los pueblos germánicos, en los que la historia alcanza su madurez, pues, para Hegel, sólo en los pueblos germánicos se ha tomado conciencia de que el hombre es un ser libre y que el Estado es la realización de la libertad humana. En el mundo germánico y su Estado, por consiguiente. Hegel consideró que la historia habfa llegado a su fin, como fin último del Espiritu Absoluto's?.

Para el supuestamente "hegeliano" Fukuyama, el capitalismo neoliberal es el último estadio del proceso histórico universal. Es el sistema en el que los hombres se encuentran plenamente satisfechos. "Si la historia nos lleva, de un modo u otro, hacia la democracia liberal, esta cuestión se conviente, entonces, en la de la bondad de la democracia liberal y de los principios de libertad e igualdad en que se basa..." "24, afima Fukuyama. Pero su discurso no sólo es provocador sino también cínico. Es revelador, dice Gorostiaga, "que cuando se anuncia el $<<f i n$ de la historia > y el triunfo del sistema capitalista occidental, el Banco Mundial publique el Informe sobre Desarrollo Humano 1990: La pobreza como la <<cuestión más apremiante de la década〉>. El fenómeno de los 1,000 milllones de personas con un per cápita menor de 370 dólares al año no es solamente vergonzoso, sino insostenible"2s. No obstante, para Fukuyama la Historia se ha cerrado, $y$ ante esto, Hinkelammert reconoce:

"El mundo que ahora aparece y se anuncia, es un mundo en el que existe un solo señor y amo, y un solo sistema. Tenemos un mundo con un solo imperio, que llega a todas partes... Llega a tener el poder total, y eso lo sabe. Y en lodas partes el imperio comunica que tiene todo el poder. La autoproclamada <<sociedad abierta>> constituye la primera sociedad cerrada, de la que no existe ningún escape hacia fuera" ${ }^{\prime 26}$.

Cierto, Hinkelammert está plenamente consciente de que en lugar de un pluralismo de sistemas y soluciones, en el mundo se ha impuesto un solo sistema y una única solución: la capitalista neoliberal. Estamos ante una homogeneización de la sociedad mundial. Pero esto no significa que no deban haber resistencias a este sistema todo poderoso y aplastante:

"No hay mundos, sino que el capitalismo homogeneizado es el mundo. A pesar de los cambios vertiginosos que siguen ocurriendo, aparece la resignación para unos y el aburrimiento postmoderno para otros. Pero aparece también una reformulación general de la resistencia al sistema y de las perspectivas alternativas para el futuro"??

Pero, a la par de este problema de las resistencias y las alternativas, hay otro que plantemos con las siguientes preguntas. ¿Qué hay realmente tras el triunfo del capitalismo? ¿Es en verdad una victoria total la que se ha ganado, sin costo alguno para los vencedores? Ante estas intertogantes, nuestro autor responde:

"El sistema aplasta; no obstante, ese aplastamiento produce reacciones. La victoria ha sido total, pero se hace sentir una realidad: que la victoria total 
lleva en sus entrafias la derrola. La victoria pareee peor que una victoria de Pirro. Pirro, un rey de la antigledad, dijo despues de su victoria: otra victoria igual y estoy perdido. Se cuidó de tener otra victoria igual, y siguió siendo rey. El capitalismo total, en cambio, ganó otra victoria igual, la segunda victoria de Pirro. Por ende está perdido. No está perdido a pesar de tener todo el poder. Está perdido precisamente porque ha logrado tener todo el poder. Es una sociedad sin rumbo que esconde su debilidad detrás del escudo de sus golpes de fuerza..."n".

Hay dos elementos fundamentales, por tanto, que explican la derrota del capitalismo y son: la crisis del desarrollismo y el hecho de que el sistema capitalista haya sobrepasado los limites de su crecimiento. Estas crisis son parte de una misma y única crisis, es decir, la crisis de la cultura occidental y, por ende, del mundo en general. ¿Por qué? Porque Occidente ha venido occidentalizando el planeta desde el siglo XVI y, en el presente, enfrentamos la crisis de civilización de una humanidad occidentalizada. Veamos en seguida, y rápidamente, esta preocupante realidad.

\section{Crisis del desarrollo y culturn de la desesperanza}

Para Hinkelammert, si de los afios cincuenta hasta los setenta el capitalismo mostró un rostro humano, hoy en los noventa ya no necesita hacerlo. Hoy su rostro es cínico y salvaje. Cínico porque ya no le importa aceptar abiertamente lo que ayer ocultaba con gran celo: su injusticia, su falta de hurnanidad. Salvaje porque en nombre de su crecimiento económico no le importa destruir a los humanos ni a la naturaleza. Este nuevo rostro es bien claro en la aplicación de sus políticas desarrollistas en América Latina.

Desde los años cincuenta hasta los setenta, el desarrollismo implementado en América Latina se inspiró en el Estado de Bienestar, tal como surgió en Europa Occidental. El desarrollo se entendió, en ese entonces, como desarrollo propiamente industrial, con el cual se esperaba obtener una fuerza de trabajo mayor que a la vez produjera un crecimiento económico que aumentara los salarios. Se Irataba de un política redistributiva de los ingresos, apoyada por una serie de leyes sociales, en el campo de la educación, la salud, la vivienda popular, etc... Este era el modelo de capitalismo de reformas que existía en Europa Occidental. y que se intentó trasladar a América Latina mediante la industrialización del continente:

"El concepto de desarrollo subyacente al de desarrollismo, era de armonía. Se suponfa la posibilidad de un desarrollo económico rápido, cuya consecuencia inerte serfa la integración económica de toda la población. Una polftica social adecuada aseguraria la traducción de la integración económica de la población en una integración social, lo que crearra la base para un consenso democrático que sustentara la democracia liberal de masas emergente. 
No obstante, al fallar la polícica de industrialización no se dio la integración económica de la población. Surgió una población expulsada creciente, se quebró el consenso democrálico. La democracia liberal de masas no resultó posible en los términos en los que se créa que existra en Europa Occiden(al"'?".

El modelo fracasó. Los paises que sirvieron como ejemplo para la polftica de industrialización, como México, Brasil y Argentina, están, en la actualidad, entre las naciones más endeudadas del Tercer Mundo. Además, hay en estas sociedades un gran desequilibrio entre una minoría enormemente rica y grandes mayorías terriblemete pobres.

"El capitalismo salvaje que regresa con la estrategia neoliberal a partir de la década de los setenta, no enfrenta ninguno de los problemas crticos que provocaron la crisis del desarrollismo latinoamericano. No enfrenta el problema de crear una industria capaz de lanzarse de forma competitiva al mercado mundial, ni el de la población expulsada. Renuncia a la intustrialización, por un lado, y decide callar a la población por medio del tritorismo del Estado, por el otro. Hablando todo el tiempo de la eficiencia, dice adiós a ella y reduce a América Latina otra vez a la exportación de materlas primas y de alimentos. En vez de superar el subdesarrollo, se sueña con una eficiencia subdesarrollada" ${ }^{30}$.

Desde los cuarenta hasta comienzo de los setenta, America Latina conoció una cierta cultura de la esperanza. Esta cultura, sostiene Hinkelaintitert, inspiro a distintos partidos políticos como los populistas, socialdemocrates y demócratacristianos, como también a las corrientes socialistas del continente. Pero, tras el fracaso del desarrollismo y del aplastamiento por parte del imperio de aquellos gobiernos de tendencia socialista, como el de la Unidad Populer de.Chile y el de la Nicaragua sandinista, que buscaron el desarrollo por vfas no capienlietas -resistiendo únicamente Cuba, pero agobiada por "un bloqueo econorico inmisericorde de Estados Unidos"-, la instalación de dicladuras de Seguridad Necional y las "guerras de baja intensidad" en Centroamérica, nace y va creciendo, en todo el continente, una cultura de la desesperanza.

En el contexto del fracaso del desarrollismo latinoamericano, se ha dado, entonces, una doble crisis: no se logro la inserción de la industria latinoamericana en los mercados mundiales y se falló en el objetivo de integrar a la totalidad de la población en la división social del trabajo. Y el resultado de esta situación es, asegura Hinkelammert:

"El resultado fue la crisis de la balanza de pagos, por un lado, y de la población expulsada, convertida en sobrante, por el otro. En esta situación se desarrolló la cultura de la desesperanza"3!. 
Pero la cultura de la desesperanza no es sólo del Tercer Mundo. Tambien es una cultura que se ha venido globalizando. Ha tocado las puertas del Primer Mundo y ya está dentro de este. La crisis del desarrollismo occidental es mundial. Veamos cómo lo explica Hinkelammert:

"Sin embargo, la profundidad de la crisis del desarrollo se mostró cuando ella penetro en las propias sociedades capitalistas del centro. Incluso estas sociedades de alto crecimiento económico y desarrollo de la técnica, fueron incapaces de lograr un arrastre tal de la dinámica económica que la población entera fuera integrada como su consecuencia. A partir del decenio de los setenta sube el desempleo en estos países, hasta que aparecen poblaciones expulsadas y excluidas también alli. El desempleo resulta ahora crónico, estructural, y ya no cíclico como lo fuese en el siglo XLX...

(...) Eso lleva a una crisis del desarrollo que pone en cuestion de manera efectiva, todo aquello que desde siglos se habla esperado como resultado: la armonfa entre el desarrollo humano y la maximización del crecimiento económico basado en el desarrollo ícnico... Si bien esta población excluida existe en los centros de desarrollo en menor cantidad, lo cierto es que ella aparece ahora en todas partes del mundo sin excepción. El sisterna se cierra, a pesar de no dejar a nadie vivir fuera de él.

Emerge entonces un mundo caracterizado por el desarrollo desigual, del cual ya no hay escape..." 3 .

"El desarrollo se ha estancado a nivel intemacional. Una cultura de la desesperanza es lo que se desarrolla mundialmente. Los países ex socialistas experimentan, desesperanzados, el derrumbe de sus industrias y su expulsiónexclusión del sistema capitalistan al cual deben integrarse. Países europeos de larga tradición industrial como Inglaterra se mueven, en ciertos aspectos sociales, hacia el subdesarrollo. El número de naciones industrializadas no aumenta. Lo que aumenta por todas partes es el desempleo, la criminalidad organizada, el narcotráfico, las pandillas juveniles delicuentes, etc...

El propio desarrollo, como industrialización con competitividad en el mercado mundial, se ha estancado. Se está transformando en un gran enclave industrial inserto en un mundo caracterizado en su mayor parte por la expulsión y exclusión de la población. Todo el mundo está dominado, sin embargo, la dominación no necesita a los dominados sino que los considera como sobrantes y los trata como tales. Este enclave industrial es altamente dinámico en sf, pero no muestra capacidad de extensión más allá de sus límites" ${ }^{\prime 33}$.

Sin embargo, la desgracia de los muchos es el contento de unos pocos. Pues crisis del desarrollo no significa crisis del gran capital y del señor mercado, sino todo lo contrario, como lo expone nuestro autor: 
rriendo en la realidad por la destrucción acumulativa de la naturaleza. Es como la fiesta que se celebraba en la Edad Media después del estallido de una peste. Una vez empezaba una peste, la gente se juncaba para la fiesta y bailaba hasta que el último cala muerto" ${ }^{\text {"4. }}$.

Hinkelammert lamenta el hecho de que vivimos en un mundo que no admite alternativas ni valores que pongan en cuestión el sistema capitalista neoliberal. Porque al excluir otras alternativas, esta sociedad destruye los valores y posibilidades que podrían posibilitar su propia sobrevivencia futura. Esto lo atestigua el hecho de que hoy nos dice:

"En el mundo occidental burgués, retorna la celebración del herolsmo del suicidio colectivo. No se puede vivir en una sociedad sin alternativas, a no ser que se acepte como un herolsmo la catástrofe que se anuncia. Por ello, se extiende de nuevo una cultura del suicidio colectivo" ".

Citando a Marx. Hinkelammert sostiene que, al igual que Meadows y su equipo, éste creía que la toma de conciencia con referencia a la destrucción llevaría a la humanidad a su conversión y así a la búsqueda y aceptación de nuevas altemativas de sociedad, desartollo y vida:

"Pero es evidente que éste no es el caso. La humanidad puede aceptar y celebrar su suicidio colectivo. Existe en la acualidad una tendencia clepra de este tipo. De allí que Nielzsche vuelva a ser de nuevo nuestro clásico. En Marx se puede leer lo que hemos perdido. En Nietzsche adonde vamos. A la utopfa de la cual se afirma que porque quiere el cielo en la tierra produce el infierno, nuesura sociedad sin alternativas opone la mística del suicidio colectivo. A la posibilidad del infiemo en la tierra, opone su seguridad. Para ma ser sorprendido con los ojos cerrados por la utopía, se marcha al infiemo con los ojos abiertos. Nuestra sociedad lo toma en serio, no admite ninguna alternativa"4".

La condición humana actual no es para Hinkelammert la de, un simple heroísmo sino más bien la de un pesimismo postmoderno que goza. palológicamente, del suicidio colectivo de la humanidad.

En una entrevista a Meadows, en la que se le pregunuo si po le gustarla volver a realizar un trabajo parecido a su informe "Los límiles del crecimiento", respondio: "Suficiente tiempo he tratado de ser un evangelista global, y he tenido que aprender que no puedo cambiar el mundo. Adernás, la humanidad se comporta como un suicida, y no tiene sentido argumentar con un suicida una vez que ha saltado de la ventana"42.

Es claro, entonces. que la crisis de civilización de la cultura occidental no sólo es evidente en la política de desarrollo y en su incapacidad de asegurar un desarollo justo y equitativo en la comunidad internacional. También es claro en la crisis del medio ambiente, la cual revela a su vez un If́mile implícito para cualquier tipo de desarrollo por crecimiento económico con pretenciones ilimitadas, 
pues, vivimos en mundo finito y con recursos naturales limitados. Sin embargo, el sistema capitalista no parece entenderlo así, con su racionalidad instrumental:

"Ningún criterio de escasez del mercado anuncia que se está llegando a un límite de lo posible. Solo el colapso podría mostrarlo, pero lo demostraría únicamente porque ya se hubiese pasado un punto de no retomo... Antes del colapso el mercado aún florece, aunque las condiciones de vida ya hayan sido destruidas. El verde del dólar cubre el verde de la naturaleza, hasta que la muerte de la naturaleza lo haga palidecer" ${ }^{\text {"3? }}$.

Pero el capitalismo triunfante celebra el aumento de su eficiencia y de su racionalidad económica, sin reconocer la derrota que arrastra en sus propias entrañas:

"Celebramos la racionalidad y la eficiencia, no obstante estamos destruyendo las bases de nuestra vida sin que este hecho nos haga reflexionar sobre los conceptos de racionalidad cortespondientes. Somos como dos competidores que están sentados cada uno sobre la rama de un árbol, cortándola. El más eficiente será aquel que logre cortar con más rapidez la rama sobre la cual está sentado. Caerá primero, pero ganará la carrera por la eficiencia.

Esta eficiencia, ¿es eficiente? Esta racionalidad económica, ¿es racional?"ma

Esta es, nos dice Hinkelammert, la racionalidad neoliberal delirante que Charles P. Kindleberger propaga en su obra Manias, Panics and Crashes: $A$ History of Financial Crises, con la frase lapidaria: "Cuando lodos se vuelven locos, lo racional es volverse loco también" ".4. Dicha frase fue central en la película Exterminator $I I$. Es la irracionalidad de la racionalidad instrumental la que gobierna el mundo.

"Se requiere una alternativa, La razón de la necesidad de una altemativa no es un simple deseo romántico ni una simple aplicación de una ética derivada de algún Sinal. Emerge como una necesidad en el momento en que nos decidamos a asegurar la vida futura de nuestros propios hijos. Presupone el rechazo a volvernos locos también.

No obstante, la sociedad moderna -en la actualidad, toda la sociedad moderna es burguesa - se lanza a destruir cualquier intento de buscar alternativas... Se lanza a pique en el sagrado sepulcro de sus mercados tolales. Todo lo transforma en una mascarada de su mística del suicidio colectivo de la humanidad"4s

\section{El cautiverio de la utopia}

El socialismo soviético fue un intento de solución a la crisis del capitalismo en el marco de la conservación de la civilización occidental. Pero esta vía no capitalista fracasó: 
"El colapso del socialismo soviético demuestra que éste no era la altemativa necesaria para responder a la crisis del capitalismo. La victoria del capitalismo, en cambio, muestra que la crisis de éste es la crisis de la civilización occidental. Es una victoria de Pirto, una victoria aparente en la que el vencedor resulta ser el derrotado. Superar la crisis del capitalismo nos lleva a la necesidad de ir más allá de la civilización occidental y de su modernidad misma"d?.

Es necesario buscar una altemativa más allá de la cultura occidental. Pero, el problema, asegura Hinkelammert, es que a toda otra altemativa se la calificará de utópica en un sentido altamente peyorativo:

"De cualquier altemativa se dirá que es utópica. Sin embargo, dentro de la visión de las ulopías a partir de la eficiencia formal eso significa que quieren hacer el cielo en la tiema, y que sólo producen el infiemo. La utopía es vista como diabólica, de ahi que se demande un exorcismo para controlar a los demonios, tal como Popper lo hace de modo explícito..." 4 .

Se Irata, pues, de buscar una alternativa a una civilización que se ha desarrollado por varios siglos, y que ha logrado conquistar el mundo entero en los últimos 500 años. Es una civilización que ha venido prometiendo el sueño utópico de lograr una ammonla entre el progreso técnico y el humano, pero que hoy se ha vuelto una pesadilla de la que no se quiere despertar. Se niega la posibilidad de cualquier otra alternativa a la cultura occidental $y$, aparentemente, lo único que queda es el suicidio colectivo que arrastra consigo el capitafismo neoliberal:

"La sociedad burguesa se cerró a esta disyuntiva. Celebro al dermumbe del socialismo soviético como su victoria final, incluso como el fin de la historia. Sin embargo, la propia legitimidad de esta sociedad esta hoy en juego. Al cerrarse a la discusión de altemativas, ella tiene que cerrer su propia capacidad de pensar su futuro y el futuro de la humanidad. Tiene que dejar de analizar las realidades para refugiarse en la afirmación ciega de principios puros.

Solamente esta situación puede explicar por qué en el grado en el cual la crisis aumentaba y la disyuntiva resultaba visible, la sociedad burguesa se definfa por una teoría económica como el pensamiento neoliberal. Para poder continuar, la sociedad burguesa tiene que negar la realidad. Los grandes problemas del mundo - la exclusión de la mayoría de la población mundial y de la naturaleza, ambas por la ciega maximización del crecimiento económico- deben ser expulsados del pensamiento teórico para que no haya cuestionamiento del sistema. Lo que se expulsa en la tierra, es expulsado también en el cielo de esta teorla"49.

Ciertamente, el neoliberalismo no habla más de la realidad humana, social y polf́tica con seriedad y profundidad. Su única voz es hablar del mercado y su 
sagrada ley de la oferta y la demanda que "todo lo regula"; como si éste no existiera en una realidad concreta de hombres de carne y hueso con necesidades vitales, y en el contexto de una naturaleza finita y además destruida que ya no da para más pillaje y explotación irracional. Y tras esta teorfa neoliberal subyace una antropologia que le es propia y que Hinkelammert describe muy bien:

"Vistos desde la teoría neoliberal, los humanos no tienen necesidades sino apenas propensiones a consumir, inclinaciones psicológicas que originan sus demandas. Se desenvuelven en una naturaleza que no es más que un objeto de cálculo... El sujeto humano concebido por la teoría neoliberal es un perfecto solipsista. En su raíz es una billetera caminante, que usa como brújula una computadora que calcula maximizaciones de las ganancias... Este sujetobilletera con mente de calculadora se imagina que existirá aunque este mundo no exista. Es un ángel que se dejó seducir por los esplendores de este mundo y que gime por volver a su estado puro. Es un homo economicus"so.

Es falsa, entonces, la idea de que las utoplas hayan muerto. Los hombres no podemos vivir sin utopías. Y lo cierto, más para mal que para bien, es que estamos ante "el eterno retomo de lo nuevo": la utopla burguesa. La misma utopla sólo que con un nuevo nombre: neoliberalismo. Y con una nueva cara: el rostro cínico e inhumano del capitalismo salvaje. Pues, con la política neoliberal de las décadas de los setenta y ochenta, retoma ese siempre "nuevo y topoderoso utopismo" burgués que promete un mundo mejor para la humanidad, pero hoy bajo el estandarte de la globalización y la liberalización total de los mercados y del capital:

"Se sueña con la política del 《<choque〉> que todo lo despedaza, para lograr así un mundo glorioso por venir en nombre de cuya vanidad prometida se vuelve a sacrificar el presente. La promesa nunca se cumple, por que quien hoy sacrifica el presente para el futuro, mañana lo tendrá que repetir. Cada presente, el de hoy y el de mañana, es sacrificado a su respectivo futuro"s!.

Esta es una utopia que globaliza y totaliza todo. Para Hinkelammert, el resultado de esta utopla es un capitalismo de cuartel, pues, la globalización es totalización. Una totalización que busca igualar todo en el mundo, para que el individuo sea realmente un ser individual. Un ser "individual", en este sentido, es un ser idéntico en todas partes, donde todos comemos "Big Mac" y tomamos "Coca Cola". Y el lema publicitario de esta bebida lo dice todo: "Si usted no conoce esıa forma (la de su botella) y este sabor: ¡Bienvenido al planeta tierra!".

Pero esta utopía burguesa es en realidad una antiutopía. La utopía conservadora del capitalismo neoliberal no es más que eso, asegura Hinkelammert, una antiutopía. Pues no se trata de una utopía crítica sino de una utopia que husca conservar el sfatu quo burgués, pero prometiendo siempre un mundo mejor para todos. En este sentido, es una utopía transformada en ideología que busca secu- 
larizar una sociedad entera. El capitalismo neoliberal se siente como la gran utopfa prometida y hoy realizada, es decir, ya no se mira como utopía sino como pura realidad, por eso, afirma, que hemos llegado al final de las utopfas y de la historia misma:

"Por eso, en nombre de la utopla conservadora esta sociedad declera ser una sociedad para la cual no hay altemativas. La crítica busca altemativas; la negación de la crítica, en cambio, se deriva de la tesis de que la sociedad afirmada es la única alternativa para la cual no existe ninguna otra. La crítica es transformada en algo absurdo, en un asunto de tontos o de traicioneros.

De alli que las sociedades que se legitiman mediante utopias conservadoras, sean expresamente antiutopías. La utopía conservadora siempre se hace presente en nombre del realismo...

(...) Cuanto más la sociedad se utopiza y se presenta como única alternativa para la cual no hay ninguna ora $y$, por tanto, se hace pasar como fin de la historia, tanto más ataca como utopistas a quienes mantienen la cabeza fría y siguen siendo críticos. Incluso los diaboliza a la manera que Popper inurodujo en el Mundo Libre: quien quiere el cielo en la tierra, produce el infiemo en ella":?2.

\section{Utopía y realidad}

Para concluir este artículo, hay que decir que Hinkelammert considera que las utopías son parte de la condición humana. No su juicio no hay pensamiento humano fuera del horizonte utópico. En su filosofía está fuera de luger la discusión de si hay que tener utopía o no, el problema está, a su parecer, en dejar de ser crílico frente a las utopías y caer en una ingenuidad ulópica. Para él, lo fundamental es realizar una relación realista entre lo utópico y sus posibles horizontes de realización concreta. Es decir, que las utopías, con su "cómo deberían ser las cosas", no ignoren y oculten "cómo son en realidad las cosas en el mundo". De ahí que en una de sus obras, Crítica a la razón utópica, del año 1984. Hinkelammert se haya dedicado a tan delicado tema, haciendo una crítica a la razón utópica, no en el sentido de una critica demoledora sino de crítica en el sentido kantiano, y tampoco en el sentido de rechazar lo utópico, sino, como él mismo dice, en el sentido de analizar los marcos categoriales, dentro de los cuales se elaboran los pensamientos sociales utópicos, los cuales, estima, contienen siempre una reflexión trascendental. Pues las utoplas también pueden translormarse en lo que él llama fuerzas destructoras. Sobre todo hoy, cuando la ingenuidad utópica, que parecía en crisis, no es superada, y ésta vuelve, con su potencialidad destructora, como antiutopia, es decir, vuelve "en nombre de la utopía de una sociedad sin utopías", como es la ingenuidad utópica que subyace tras el pensamiento neoliberal, pues cree estar más allá de toda utopía cuando en cl Condo es una utopía más". Ahora bien, si la utopía es condición humana, ella 
es, para Hinkelammert, la conceptualización de una sociedad que está más allá de la condición humana histórica y cultural en que se está.

Por lo tanto, nuestro filósofo está consciente de que el pensamiento utópico ha acompañado siempre al hombre a todo lo largo de su historia, y que los hombres siempre han buscado "una escalera que va de la tierra al cielo". Por consiguiente, está consciente de que la abolición de las utoplas es imposible, pero considera a la vez que también su realización ha sido imposible. Es por esta razón que su pensemiento no cee en una ingenuidad utópica. $Y$ por ello su obra no es un conjunto de libros de recetas o soluciones definitivas y cerradas. Su obra intelectual es un analisis filos6fico y cient/fico sobre la realidad histórica y cultural actual, en la que desde hace buen tiempo viene trabajando en una critica a la ingenuidad utópica del presente $y$, en particular, a esa ingenuidad utópica del pensamiento antiutópico de la tradición neoliberal.

¿Qué hacer, entonces, en un mundo postmoderno y mercadocentrista cuya racionalidad economicista nos está llevando por el camino de la muerte? Hinkelammert no pretende tener una teorfa mágica con la cual pueda brindar a la humanidad una gula a seguir para que ésta logre encontrar "la escalera que conduce de la tierra al cielo". Su respuesta es muy realista:

"Hoy, cualquier alternativa es imposible. Eso es así porque hay poderes capaces de destruirlas, y decididos a hacerlo. Por tanto, si orientamos un proyecto de liberación según estos criterios de poder, no se puede hacer nada"s.".

Pero, pensando en una posible salida, para la sobrevivencia misma de la humanidad, en su obra, Cultura de la esperanza y sociedad sin exclusión, indica algunas líneas que se pueden seguir para detener este carrusel de la muerte en el que jugamos a grandes velocidades: (1) relativizar el rol de la competitividad; (2) crear espacios de desarrollo en los que el empleo y la distribución de los ingresos no se espere más de un efecto del crecimiento económico; (3) integrar el crecimiento económico con el de la naturaleza"s

Sin embargo, reconoce que las posibilidades de lograr estas melas son poco probables:

"Los espacios económicos capaces de solucionar esta tarea imponen un nuevo lipo de integración económica que ni la Comunidad Europea, ni la integración económica desarrollista, y menos la actual integración por zonas de libre comercio, han experimentado. En todo caso, se Irata de una tarea de sobrevivencia de la humanidad".".

En su más reciente obra, Determinismo, caos, sujeto. El mapa del emperador, pone a la solidaridad humana como una actitud lundamental para todo cambio, por ser ésta necesaria y útil. Pero, advierte que, a pesar de ser una necesidad que puede salvar a la humanidad, la solidaridad con los otros no es algo inevitable en la sociedad mercadocentrista y capitalocentrista actual: 
"La solidaridad es necesaria, pero ella no es inevilable. Es necesario enfrentarse a las fuerzas compulsivas de los hechos para disolverlas. Estas fuerzas son inevitables, pero someterse a ellas es destructor y, en última instancia, autodestructor. Se puede enfrentar este proceso de destrucción solamente disolviendo las fuerzas compulsivas de los hechos. Sin embargo, eso únicamente es posible por una acción solidaria.

Por eso, la solidaridad es necesaria. Pero no es inevitable. Se pude afirmar este proceso de destrucción y sostenerlo, aunque implique el suicidio colectivo. La necesidad de evilar este proceso de destrucción resulta de una necesidad afirmada en la libertad. El sometimiento a las fuerzas compulsivas de los hechos, en cambio, implica la pérdida de la libertad junto con la afirmación de un proceso de autodestrucción colectiva.

Lo que trasforma la solidaridad en algo necesario, que no por eso es inevitable, es la posibilidad del suicidio, sea individual o colectivo. En este sentido de "necesidad" se podría decir asimismo: es necesario no cometer suicidio. No obstante el suicidio no es inevitable. Por eso la necesidad de la solidaridad no resulta de ninguna ley de causalidad...

Por eso la necesidad responde al deber de una necesidad. Hay que hacer lo que es necesario.

Por ser necesaria, la solidaridad es útil. No es un valor "idealista" con validez "de por sf'. Sin embargo, se trata de algo útil que se encuentra en una tensión con cualquier cálculo de utilidad...

Pero disolver este proceso destructor es útil. Ello presupone una acción que se extrae del cálculo de utilidad, para pasar más allá de él y entrar muchas veces en contradicción con él. El cálculo de utilidad lleva a la deforestación de la Amazonia. No obstante es útil no deforestarla. Es útil no destruirla, pero se trata de una utilidad que no es calculable por el hecho de que el mismo cálculo de utilidad lleva a su destrucción. Si se intenta reducir toda utilidad al cálculo de utilidad, se socava a la sociedad entera"'?"

He aqui, pues, el pensamiento crítico de uno de esos filósofos vigilantes que lanzan a la humanidad, haciendo una crítica radical a la cultura occidental, un grito de alerta, con sus análisis filosófico-científicos sobre la uriste y peligrosa realidad histórica y cultural en que nos encontramos. Ojalá tomemos en serio su llamado a entrar en razón, es decir, su invilación a luchar por dejar ese carrusel de la mucrie, tan veloz e interesantc, en el que estamos montados a la fuerza y, a la vez, porque nos gusta, y que construyamos un mundo diferente, aunque sca menos intercsante y veloz que éste, pero si más humano y justo y, por supuesto, en el que todos qucpamos. Su mensaje es, pues, un mensaje realista; no dernagogo. Invita a crear una cultura de la esperanza y una sociedad sin exclusión; en lugar de seguir con cl heroísmo del suicidio colcctivo que experimentamos. De 
cada uno de nosotros depende tal opción, en distintos modos y grados... Además, no se puede pasar por alto el hecho, querrámoslo o no, de ser seres, finalmente, condenados a optar ya que, como dijo el fílósofo francés Jean-Paul Sartre (1905-1980), "oplar por no oplar es ya una opción". Y si a nivel personal y colectivo optamos únicamente por reír y seguir dis[nutando del juego tan divertido y entretenido de seguir produciendo y consumiendo al infinito en un planeta cuyos recursos naturales son finitos, en nombre de eso que Hamamos "desarrollo", entonces, finalmente tan sólo quedará la risa, mas, parrafraseando al filósofo italiano, Giorgio Colli (1917-1979), hay que decir que sf, que tan sólo quedará, ni modo, reír, "pero la risa es un espasmo expresivo. Los dados han sido lirados y todavía giran: sin embargo, cuando se detengan, mostrarán algo que no es un juego".

\section{Notas}

I. López Gil, Marte. Obsesiones filosdficus de fin de siglo, Buenos Aires: Editorial Biblos, 1993, p. 12.

2. Kant, Inmanuel. "Respuesta a la pregunta: ¿Qué es la llustración?", en VV.AA, ¿Qué es la llustración?. Madrid: Bditorial Tecnos, 1993, p. 17.

3. Cfr., Bury, John B. La idea de progreso, Madrid: Alianza Editorial, 1971, p. 177.

4. Ibid., pp. 189-190.

5. Citado por Jose María Mardones, en El desafio de la postmodernidad al cristianis. mo. Santander: Editorial Sal Terrae, 1988, p. 9 :

6. Lyotard, Jean-Francois. La condition poshinodeme, Paris: Editions de Minuit, 1979.

7. Cfr., Habermas, Jurgen. "La modemidad: un proyecto inacabado", en Ensayos políi. cos, Barcelona: Ediciones Peninsula, 1988, pp. 265-283.

8. Nietzsche. Friedrich. La volunead de poderio, Madrid: EDAF, 1981, p. 31.

9. Heidegger, Martin. "La pregunta por la tecnica", en Epoca de filosofia, 1, 1, Barcelona.1985, pp. 7-8.

10. Sobre la posmodernidad pueden consultarse: Lyotard. Jean-Francois. La condición postmoderna, Barcelona: Editorial Ptaneta, 1993; Mardones, José María. Posimodemidad y cristianismo. El desafio del fragmento, Santander: Sal Terrae, 1988: Pico. Josep. Modernidad y posimodemidad, México: Alianza Editorial. 1990; GonzálezCarvajal, Luis. Ideas y creencias del hombre actual. Santander, Sal Terrae, 1992; López Gil, Marta. Obsesiones filosóficas de fin de siglo. Buenos Aires: Editorial Biblos, 1993; Beyme. Klaus von. Teoria política del siglo XX. De la modemidad a la pustmodernidad. Madrid: Alianza Editorial, 1994: Vattimo. Gianni y otros, En corno a la posmodernidad. Barcelona, Editorial Anthropos. 1994.

11. Hinkelammert. Franz J. Determinismo, caos, sujeto. El mapa del emperador, San José: DEI, 1996, p. 12.

12. lbid.

13. Hinkelammert, Franz J. Cultura de la esperanza y sociedad sin exclusion, San José: DEI, 1995. p. 148.

14. Ibid., p. 148.

15. Ibid., pp. $148-149$. 
16. Según fuentes del Banco Mundial, y citadas por el economista suizo Ruddolf $H$. Strahm, en 1980, los palses del Primer Mundo contaban con un 26 por ciento de la población humana que consumfa el 78 por ciento de lo que se producla internacionalmente; mientras que en el Tercer Mundo, con un 74 por ciento de la población mundial, no se disponla sino de un poco más del 20 por ciento, o una quinta parte de la producción y las riquezas mundiales. En otros terminos, esta disparidad se reflejaba en el sobreconsumo de energla: el consumo de energía de I estadounidense equivalla al de 2 europeos, 55 habitantes de la India, 168 de Tanzania o 900 de Nepal. Cfr. R. H. Strahm, Pourquoi sont-ils si pauvres? Faits et chiffres en 84 lableaux sur les mecanismes du developpement, Boudry (Suisse): Editions de la Baconniere. 1986, pp. 12-15.

17. Según el Programa de las Naciones Unidas pera el Desarrollo (PNUD), "una quinta parte de la humanidad, principalmente en los paises industrializados, cuenta así con las cuatro quintas partes del ingreso mundial y otras oportunidades de desarrollo. Esa disparidad refleja muchas otras, en materia de comercio, inversión, ahorro y crédito comercial. En general, refleja un desigual acceso a las oportunidedes del mercado a escala mundial. Esas disparidades tienen consecuencias en otros aspectos de la seguridad humana. Estimulan el consumo excesivo en el Norte y perpetúan el vínculo entre pobreza y medio ambiente en el Sur...". PNUD, Informe sobre desarrollo humano 1994, p. 40.

18. Citanto fuentes del Worldwatch Institute de Estados Unidos, el teologo Leonardo Boff expone: "el ser mas amenazado de la naturaleza hoy en dla es el pobre. El 79 por ciento de la humanidad vive en el Gran Sur pobre; 1000 millones de personas viven en estado de pobreza absoluta; 3000 millones (de 5300 millones) tienen una alimentación insuficiente; 60 millones mueren anualmente de hambre y 14 millones de jóvenes de menos de is años mueren anualmente a consecuencia de enfermedades derivadas del hambre. Frente a este problema, la solidaridad entre los seres humanos es prácticamente inexistente. La mayoría de los parses ricos ni siquiera destina el 0.7 por ciento de su Producto Interno Bruto (P1B), precepluado por la ONU, a la ayuda de los paises necesitados. El pals más rico, Estados Unidos, destina únicamente el 0.15 por ciento de su PIB", Boff, L. Ecologla. Grifo de la tierra. Grito de los pobres, Madrid: Editorial Trotta, 1996. p. 13.

19. Gorostiaga, Xavier. "América Latina frente a los desaflos globales. Los 90: Una coyuntura estratégica", en X. Gorostiaga el al., Los Cambios en el mundo, San Salvador: Istmo Editores, p. 21.

20. Cultura de la esperanza y sociedad sin exciusión, op. cir., p. 140.

21. lbid., p. 16.

22. Véase la tradueción castellana de esle artículo en la revista Claves del l de abril de 1990, pp. 85-96. Este artículo fue reconvertido en libro por su autor en 1992: Fukuyama, Francis. El fin de la historia y el último hombre. Barcetona: Editorial Planets, 1992.

23. El tema es desarrollado por Hegel en Fundamentos de la fllosofía del derecho, Madrid: Libertarias/Ptodhufi, 1993; y en La raison dans l'histoire. Introduction á la Philosophie de la l'Histoire, Paris: Union Générale DEditions, 1965.

24. Fukuyama, Francis. El fin de la historia y el último hombre, op. cit., p. 387.

25. Gorostiaga, Xabier. Los cambios en el mundo, op. cit., p. 21. 
26. Hinkelammer, Franz J. "Cultura de la esperanza y sociedad sin exclusión", op. cir., p. 27.

27. Ibid., p. 16.

28. Hinkelammert, Franz J. Cultura de la esperanza y sociedad sin exclusión, op. cis., p. 16. Nota: En cuanto a Pirro (319-272 a. de C.), hay que decir que fue rey de Epiro (Epeiros), una región del norte de Grecia, en el siglo III a. de C. Intentó crear un imperio helénico occidental. Luchó contra los romanos al apoyar a Tarento y los venció en Heraclea ( 281 a. C.) y Ausculum (279 a. C.). También se enfrentó contra Cartago. Fue derrotado por los romanos en Benevento (275 a. C.) y asesinado en Argos (272 a. C.).

29. Hikelammert, Franz J. Cullura de la esperanzo y sociedad sin exclusión, op. cit., p. 132.

30. Ibid., pp. 132-133.

31. Ibid., p. 131.

32. Ibid., pp. 136-137.

33. Ibid., p. 137.

34. Ibid.

35. Algunos detalles más amplios al respecto pueden consultarse en: Wauthion Ernesto. "Etica y desarrollo: propuestas para su relación y para un desarmollo sostenible desde una filosofía liberadora". en VV. AA., Para una filosofica liberadora. Primer encuentro mesoamericano de filosofla (1994), San Salvador: UCA Editores, 1995, pp. 23!-247.

36. Mires, Fernando. El discurso de la naturaleza. Ecología y políica en América Latina. San José: DEI, 1990, pp. 16-18.

37. Meadows. Dennis L. Más allá de los limites del crecimiento, Madrid: El pals-Aguilar, 1992.

38. Wauthion. Ernesto. "Etica y desartollo: propuesta para su relación y para un desarroIlo sostenible desde una filosoffa liberadora", op. cit., pp. 235-236.

39. Hinkelammen, Franz J. Determinismo, caos, sujeto. El mapa del emperador, op. cit., p. 118.

40. Hinkelammer, Franz J. Cullura de la esperanzo y sociedad sin exclusión, op. cit., p. 167.

41. Ibid.

42. Cilado por Hinkelammert en Culiura de la esperanza y sociedad sin exclusión, op. cir., pp. 167-168.

43. Ibid., p. 139

44. Hinkelammert, Franz J. Deserminismo, caos, sujeto. El mapa del emperador, op. cit., p. 13.

45. Cilada por Hinkelammen, en Cullura de la esperanza y sociedad sin exclusión, op. cit..p. 149.

46. Ibid., p. 149.

47. Ibid., p. 140.

48. Ibid., p. 162.

49. Ibid., p. 141.

50. Ibid., pp. $141-142$.

51. Ibid., p. 115.

52. lbid., pp. 203-204. 
53. Cfr. Hinkelammert, Franz J. Crírica a la razón usópica, San Jose: DEI, 1990.

54. Hinkelammert, Franz J. Culsura de la esperanza y sociedad sin exclusión, op. cir., pp. 152-153.

55. Cfr., Ibld., p. 152.

56. Ibid.

57. Hinkelammert, Franz J. Determinismo, caos, sujeto. El mapa del emperador, San Jose: DEI, 1996, pp. 260-261. 